\title{
Directions to the author
}

In the journal "Crystal Rescarch and Tcchnology - Kristall und Technik" as a rule the following categories of papers will be printed: original papers, review articles, short notes, and book reviews, preferentlally in English. Complete information necessary for type-setting and a "Short Title" should be added.

The manuscript should not exceed 10 pages and be type-written on one side only in the format $\mathbf{A 4}(21 \times 29.7 \mathrm{~cm})$ on white ink-proof paper, with a two-lined distance and a left-hand free edge of $3 \mathrm{~cm}$, and submitted in 2 copies. All shects of paper belonging to the contribution are continuously to be numbered.

The head of the manuscript should be arranged in this manner: initials and name of the author; institution, and title of the paper. Then two abstracts should follow, one in the original language and the second in German, English, French, or Russian, respectively.

Formulae, signs and symbols, letters etc. being wanting on the type-writer, should be distinctly written with penholder. $O$ as zero is to be underlined, the capital $O$ is not. Greek letters should be underlined with red ink. Paragraphs should be marked by indenting of at least 3 touches.

Conccrning the marking of the manuscript should be noted :

headings should be underlined, sub-headings not, and indented by 9 touches. The titles of tables are not to be underlined. Other markings in the text will be done by the editorial staff. They mean:

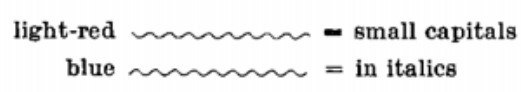

$$
\begin{array}{l|l}
\text { light-red } & \begin{array}{l}
\text { perpendicular } \\
\text { straight red line } \\
\text { on the left edge } \\
=\text { small printing }
\end{array}
\end{array}
$$

Tables are to be added on separate sheets of paper at the end of the contribution.

Foot notes should be continuously written on a separate sheet of paper.

Figures (Fig.) - drawings and photographs - should be not more than 8 and submitted (2 copies) in a special envelope: photographs as white high-gloss prints (inscription on a transparent covering sheet) and drawings as distinct sketches. On the back of the submitted figures the reduction scale in tenth $(9 / 10,8 / 10,5 / 10$ e.g.), author's name, short title of the paper, and the number of the figure should be given.

Captions for the figures should be submitted on a separate sheet of paper.

References should be written without numbers in alphabetical order of the names at the end of the contribution. Cited names in the text stand for the references. The references should contain the following items, for example:

$$
\begin{array}{ll}
\text { for books: } & \text { RAST, K.: Physikalisch-chemische Rechnungen, Berlin } 1958 \\
\text { for journals: } & \text { KRAUSE, H. N., MULLER, K.: Cryst. Res. Technol. 16, } 70 \text { (1981) }
\end{array}
$$

Add, please, the short title, about 6 keywords, and the academic grades of the authors.

The authors will be sent two galley proofs of review articles and original papers. Proof reading of short notes and book reviews will be done by the editorial staff.

For each of the papers a total of 50 reprints is available free of charge. Requests for additional maximum 200 reprints (against payment) should be given together with the submitted manuscript. 